\title{
Linkage analysis of isozyme gene loci in Picea abies (L.) Karst.
}

\author{
Th. Geburek and \\ G. von Wuehlisch
}

Federal Research Centre for Forestry and Forest Products, Institute of Forest Genetics and Forest Tree Breeding, Sieker Landstraße 2, D-2070 Großhansdorf 2, Federal Republic of Germany.

In total 14 isozyme gene loci were tested for segregation in Picea abies. Single tree segregation was not significantly heterogeneous. Pooled over all trees, segregation at the Idh-1 and Pgi-2 gene loci deviated significantly from the Mendelian expectation. Out of 91 two-locus combinations 57 could be analysed for linkage. The recombination frequencies were estimated employing the maximum likelihood and the Bayesian likelihood methods. Estimations of the recombination rates confirmed the close linkage group of Got-1:Pgi-2 in Pinaceae. Also Dia-2 appears to be linked to Pgi-2 and Got-1. Moderate linkage groups of Got-2:Skdh-1 and Lap-2:Pgi-2 were found but not in all of the investigated trees.

\section{INTRODUCTION}

Segregation distortion and more effective linkage as cytophysiological devices can contribute to storage and protection of genetic variation. Knowledge about these components of the genetic system are important prerequisites for population studies. Segregation distortion for instance can thwart evolutionary processes and can bias the estimation of certain genetic parameters. Without linkage the formation of supergenes as adapted gene complexes is impossible. Linkage influences gametic phase disequilibrium and can play an important role when marker genes are used to predict genetic gains (Frei et al., 1986).

In conifers several linkage studies have been performed and some more or less closely linked loci have been established (Guries et al., 1978; Rudin and Ekberg, 1978; Adams and Joly, 1980; Conkle, 1981; Eckert et al., 1981; Cheliak et al., 1984; Cheliak and Pitel, 1985; Furnier et al., 1986; O’Malley et al., 1986; Strauss and Conkle, 1986; Muona et al., 1987; Shiraishi, 1988; Müller-Starck and Liu, in press; Geburek and Wang, submitted).

\section{MATERIALS AND METHODS}

Out of 120 genotyped mature trees of three different Norway spruce stands open-pollinated seeds of 18 multiple heterozygous trees were selected for this investigation (crop 1983/84). The forest stands are located in Schleswig-Holstein, Germany. For some trees open-pollinated seedlots of crop 1984/85 were additionally available and could be employed. The isozymes assayed, their acronyms, scored gene loci and reference of the respective genetic control are listed in table 1.

The macrogametophyte tissue was homogenized in $0.005 \mathrm{M}$ tris $/ 0.04 \mathrm{M} \mathrm{HCl}$ buffer, $p \mathrm{H} 7.5$ without any addition of enzyme-protecting agents. The raw extracts were separated by means of horizontal starch gel electrophoresis. Details of the electrophoretic conditions, gel and electrode buffers as well as staining recipes for the isozymes are given in Geburek et al. (1987). PGI was separated and stained according to Conkle et al. (1982).

For the linkage analysis 57 out of 91 possible two-locus combinations could be investigated. Table 2 shows the combinations of loci tested and the number of trees studied. On the average about 280 gametes were analysed per combination.

The statistical procedures used to test for linkage and to estimate the recombination frequency are described below: a doubly heterozygous tree produces four kinds of gametes $A_{1} B_{1}, A_{1} B_{2}, A_{2} B_{1}$ and $A_{2} B_{2}$. Parental and recombinant types of gametes are associated with the numbers of gametes in coupling (those in categories $A_{1} B_{1}$ and $A_{2} B_{2}$ ) and repulsion (those in $A_{1} B_{2}$ and $A_{2} B_{1}$ ). 
Table 1 Isozymes, acronyms, E. C. Number, number of loci scored, and references of the respective genetic control

\begin{tabular}{|c|c|c|c|c|}
\hline Isozymes & Acronyms & EC No. & $\begin{array}{l}\text { No. of gene } \\
\text { loci scored }\end{array}$ & Reference(s) of the genetic control \\
\hline Acid phosphatase & $\mathrm{APH}$ & 3.1.3.2 & 1 & $\begin{array}{l}\text { Tigerstedt (1973), Bergmann (1974), } \\
\text { Lundkvist (1975) }\end{array}$ \\
\hline Diaphorase & DIA & 1.6 .4 .3 & 1 & Muona et al. (1987) \\
\hline Glutamate dehydrogenase & GDH & 1.4.1.2 & 1 & Lundkvist (1979), Cheliak et al. (1987) \\
\hline Glutamate oxaloacetic transaminase & GOT & 2.6 .1 .1 & 2 & Lundkvist (1979), Poulsen et al. (1983) \\
\hline Malate dehydrogenase & $\mathrm{MDH}$ & 1.1 .1 .37 & 1 & Lundkvist (1979), Muona et al. (1987). \\
\hline Phosphoglucomutase & PGM & 2.7 .5 .1 & 1 & Poulsen et al. (1983). \\
\hline 6-Phosphogluconate dehydrogenase & 6-PGDH & 1.1 .44 & 2 & Poulsen et al. (1983) \\
\hline Phosphoglucose isomerase & PGI & 5.3 .1 .9 & 1 & Poulsen et al. (1983). \\
\hline Shikimate dehydrogenase & SKDH & 1.1 .1 .25 & 1 & Muona et al. (1987) \\
\hline
\end{tabular}

Table 2 Two-locus combinations and number of trees employed for the linkage analysis (upper right half) and results of statistical testing (lower left half).

\begin{tabular}{|c|c|c|c|c|c|c|c|c|c|c|c|c|c|c|}
\hline Locus & 1 & 2 & 3 & 4 & 5 & 6 & 7 & 8 & 9 & 10 & 11 & 12 & 13 & 14 \\
\hline 1. Aph-2 & & - & $3 /-$ & - & $4 / 1$ & - & $1 /-$ & - & $1 /-$ & - & - & $2 / 1$ & - & $2 / 1$ \\
\hline 2. Dia-2 & - & & - & $1 / 1$ & - & $1 /-$ & - & 一 & - & - & - & $1 / 1$ & $1 / 1$ & $1 / 2$ \\
\hline 3. $G d h-1$ & ns & - & & - & $4 /-$ & $1 / 1$ & $1 /-$ & $1 /-$ & - & - & $3 /-$ & $3 /-$ & $4 /-$ & - \\
\hline 4. Got-1 & - & $*$ & - & & - & $1 /-$ & - & $-/ 1$ & $-/ 1$ & - & - & $1 / 1$ & $1 / 1$ & $1 / 1$ \\
\hline 5. Got-2 & ns & - & ns & - & & $2 /-$ & $1 /-$ & $2 /-$ & $4 /-$ & $2 /-$ & $5 /-$ & $8 / 1$ & $5 /-$ & $3 / 2$ \\
\hline 6. $I d h-1$ & - & ns & ns & $\mathrm{ns}$ & ns & & - & $1 /-$ & - & - & - & - & $3 /-$ & $1 /-$ \\
\hline 7. Lap-1 & ns & - & $\mathrm{ns}$ & - & ns & - & & - & - & $1 /-$ & $1 /-$ & - & $1 /-$ & - \\
\hline 8. Lap-2 & - & - & $\mathrm{ns}$ & ns & ns & $\mathrm{ns}$ & - & & $2 / 1$ & - & $2 /-$ & $2 /-$ & $3 / 2$ & - \\
\hline 9. $M d h-3$ & ns & - & - & ns & ns & - & - & ns & & $1 /-$ & $4 /-$ & $5 /-$ & $2 /-$ & $1 /-$ \\
\hline 10. Pgm-1 & - & 一 & - & - & $\mathrm{ns}$ & - & ns & - & ns & & $2 /-$ & $1 /-$ & $1 /-$ & - \\
\hline 11. 6-Pgdh-2 & - & - & ns & - & ns & - & $\mathrm{ns}$ & $\mathrm{ns}$ & ns & ns & & $5 /-$ & $5 /-$ & - \\
\hline 12. 6-Pgdh-3 & ns & ns & ns & $\mathrm{ns}$ & ns & $\mathrm{ns}$ & - & $\mathrm{ns}$ & $\mathrm{ns}$ & ns & $\mathrm{ns}$ & & $5 / 1$ & $3 / 1$ \\
\hline 13. Pgi-2 & -- & $*$ & ns & $*$ & ns & $\mathrm{ns}$ & ns & $*$ & ns & $\mathrm{ns}$ & $\mathrm{ns}$ & $\mathrm{ns}$ & & $1 / 1$ \\
\hline 14. $S k d h-1$ & ns & ns & - & ns & $*$ & ns & - & - & $\mathrm{ns}$ & - & - & $*$ & ns & \\
\hline
\end{tabular}

Number before the slash $=$ number of analysed single-tree seedlots, crop $1983 / 84$.

Number after the slash $=$ number of analysed single-tree seedlots, crop 1984/85.

- $=$ Two-locus combination not tested.

$\mathrm{ns}=$ not significant.

* = significant linkage at least at 5 per cent level in at least one seed sample

However, because the breeding history of a certain tree is unknown it is not clear whether the parental category is associated with the coupling or the repulsion phase. This complicates the estimation of the recombination fraction and is disregarded in a maximum likelihood estimation of the recombination frequencies $(\theta)$, if $\theta$ is estimated as quotient of the number of the putative recombinants related to the number of all analysed gametes.

The estimation of this $\theta$ is especially biased when a small sample size is analysed and/or weak linkage is present at the respective loci combination.

$$
\text { bias }=E \hat{\theta}-\theta=f(\theta, n) .
$$

This was the reason why in this investigation a likelihood procedure was used, which considers the fact that the putative recombinants are not necessarily the de facto recombinants.

When $n_{i}$ is the number of analysed gametes of the $i$ th tree and $k_{i}$ is the number of the smaller class in repulsion or coupling phase the likelihood is denoted by

$$
L\left(\theta \mid n_{i}, k_{i}, i=1, \ldots, N\right)
$$

which is expressed for a single tree as

$$
\begin{aligned}
L\left(\theta_{1 i} \mid n_{i}, k_{i}\right)= & \left(\begin{array}{c}
n_{i} \\
k_{i}
\end{array}\right)\left(\theta_{1 i}^{k_{i}}\left(1-\theta_{1 i}\right)^{\left(n_{i}-k_{i}\right)}\right. \\
& \left.+\theta_{1 i}^{\left(n_{i}-k_{i}\right.}\left(1-\theta_{1 i}\right)^{k_{i}}\right) \text { for } k_{i}=n_{i} / 2 .
\end{aligned}
$$


The maximum likelihood estimator is that value of $\theta_{1 i}$ which maximizes $L_{i}\left(\theta_{1 i} \mid n_{i}, k_{i}\right)$ and was designated $\hat{\theta}_{1}$. The maximum likelihood estimator was found by grid search. This was done by increasing $\theta_{i}$ in $5 \times 10^{-4}$ steps starting from zero and computing the respective likelihoods.

The likelihood of $\theta$ pooled over $N$ trees is

$$
L\left(\theta_{1}\right)=\prod_{i=1}^{N} L\left(\theta_{1 i} \mid n_{i}, k_{i}\right) .
$$

The 95 per cent maximum likelihood confidence interval (CI) was determined as

$$
\begin{aligned}
& \mathrm{CI}\left(\theta_{1} \mid 95 \%\right)= \\
& \left\{\theta_{1} \mid-2 \log L\left(\theta_{1}\right)<-2 \log L\left(\hat{\theta}_{1}\right)+x_{1,0 \cdot 5}^{2}\right\}
\end{aligned}
$$

and the upper and lower borders were found by grid search.

Nordheim et al. (1983) showed that a Bayesian approach, using a prior distribution that places equal probabilities on all values of $\theta$ is superior to the maximum likelihood procedure when weak linkage is observed. Therefore an additional estimator was calculated (Jeffreys, 1961).

$$
\hat{\theta}_{2}=\int_{0}^{0.5} \theta L(\theta \mid n, k) \mathrm{d} \theta / \int_{0}^{0.5} L(\theta \mid n, k) \mathrm{d} \theta .
$$

The integrals were calculated by approximating the likelihood function by a step function.

Contingency-tables were employed for the linkage analysis and to test if the segregation at the different gene loci followed the Mendelian 1:1 expectation. Unbalanced segregation of one pair of alleles does not affect linkage analyses (Mather,
1951). Estimation of homogeneity of $\hat{\theta}$ over all trees was performed following Rao (1973, p. 389):

$$
x_{n-1}^{2}=\sum_{i=1}^{n} \frac{N_{i}\left(\theta_{i}-\theta\right)^{2}}{\hat{\theta}-\hat{\theta}^{2}}
$$

$n=$ number of trees, $N_{i}=$ number of analysed gametes for the $i$ th tree, $\theta_{i}=$ estimated recombination frequency for the $i$ th tree, $\hat{\theta}=$ overall estimated recombination frequency.

The map distance in centimorgans $(\mathrm{cM})$ was calculated after Kosambi (1944) employing $\hat{\theta}_{2}$. Before estimating this distance pooled over several trees, each single tree map distance was weighted with $G$ according to Fisher (1937):

$$
G_{i}=\left(N_{i}\left(1-4 \hat{\theta}_{i}^{2}\right)^{2}\right) /\left(\hat{\theta}_{i}\left(1-\hat{\theta}_{i}\right)\right.
$$

\section{RESULTS;}

\section{Segregation}

In total 14 isozyme gene loci were tested for segregation (table 3 ). There was no significant heterogeneity among samples for the same loci. Only at $I d h-1$ and Pgi-2 segregation distortion was significant $(P<0.05)$ resulting in allelic proportions of $324: 272$ and $567: 642$ respectively.

\section{Linkage}

\begin{tabular}{|c|c|c|c|c|c|}
\hline Isozyme gene locus & No. of trees & Alleles & Numbers & $\begin{array}{l}\text { Heterogeneity } \\
\chi^{2}(\mathrm{df})\end{array}$ & $\begin{array}{l}\text { Deviation } \\
\chi^{2}(1 \mathrm{df})\end{array}$ \\
\hline Aph-2 & 6 & $2-3$ & $300: 263$ & $5 \cdot 66 \quad 5 \mathrm{~ns}$ & $2 \cdot 43 \mathrm{~ns}$ \\
\hline Gdh-1 & 5 & $1-2$ & $474: 482$ & $5 \cdot 89 \quad 4 \mathrm{~ns}$ & $0.07 \mathrm{~ns}$ \\
\hline Got-1 & 3 & $1-2$ & $152: 128$ & $3 \cdot 22 \quad 2 \mathrm{~ns}$ & $2.06 \mathrm{~ns}$ \\
\hline Got-2 & 14 & $1-2$ & $824: 820$ & $11 \cdot 3413 \mathrm{~ns}$ & $0.01 \mathrm{~ns}$ \\
\hline$D i a-2$ & 2 & $1-2$ & $85: 87$ & $0.22 \quad 1 \mathrm{~ns}$ & $0.02 \mathrm{~ns}$ \\
\hline$I d h-1$ & 4 & $1-2$ & $324: 272$ & $5 \cdot 44$ & $4 \cdot 54 *$ \\
\hline Lap-1 & 2 & $1-2$ & $73: 80$ & 0.85 & $0.32 \mathrm{~ns}$ \\
\hline Lap-2 & 7 & $3-4$ & $375: 351$ & $2 \cdot 52$ & $0.80 \mathrm{~ns}$ \\
\hline$M d h-3$ & 6 & $3-4$ & $388: 393$ & $5 \cdot 19$ & $0.03 \mathrm{~ns}$ \\
\hline Pgm-1 & 2 & $1-2$ & $78: 79$ & 0.07 & $0.01 \mathrm{~ns}$ \\
\hline 6-Pgdh-2 & 7 & $1-2$ & $473: 499$ & $2.47 \quad 6 \mathrm{~ns}$ & $0.70 \mathrm{~ns}$ \\
\hline $6-P g d h-3$ & 13 & $1-2$ & $941: 937$ & $18 \cdot 4512 \mathrm{~ns}$ & $0.01 \mathrm{~ns}$ \\
\hline$P g i-2$ & 11 & $1-2$ & $567: 642$ & $13 \cdot 2610 \mathrm{~ns}$ & $4 \cdot 65^{*}$ \\
\hline$S k d h-1$ & 7 & $1-2$ & $429: 391$ & $9 \cdot 15 \quad 6 \mathrm{~ns}$ & $1.76 \mathrm{~ns}$ \\
\hline
\end{tabular}

Table 4 shows that the maximum likelihood and Bayes estimates of $\theta$ were very similar. Compared to the maximum likelihood estimation the Bayes estimates result in lower values when the recombi-

Table 3 Segretation at single isozyme gene loci in Picea abies

$\mathrm{ns}=$ Not significant.

$*=\boldsymbol{P}<0.05$. 
Table 4 Estimates of the recombination frequencies $(\theta)$ and measures for significance

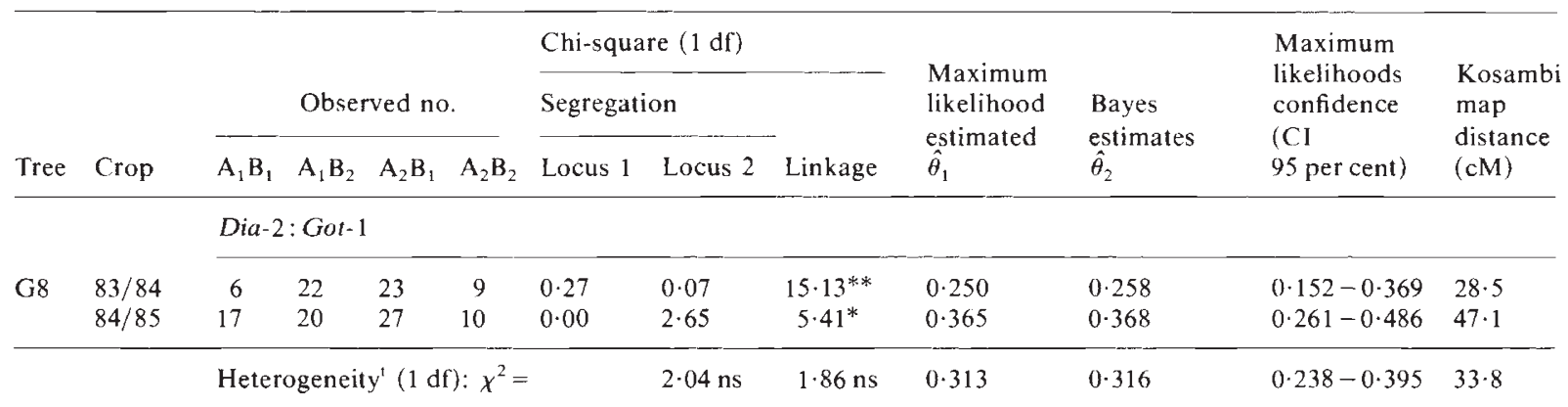

Dia-2:Pgi-2

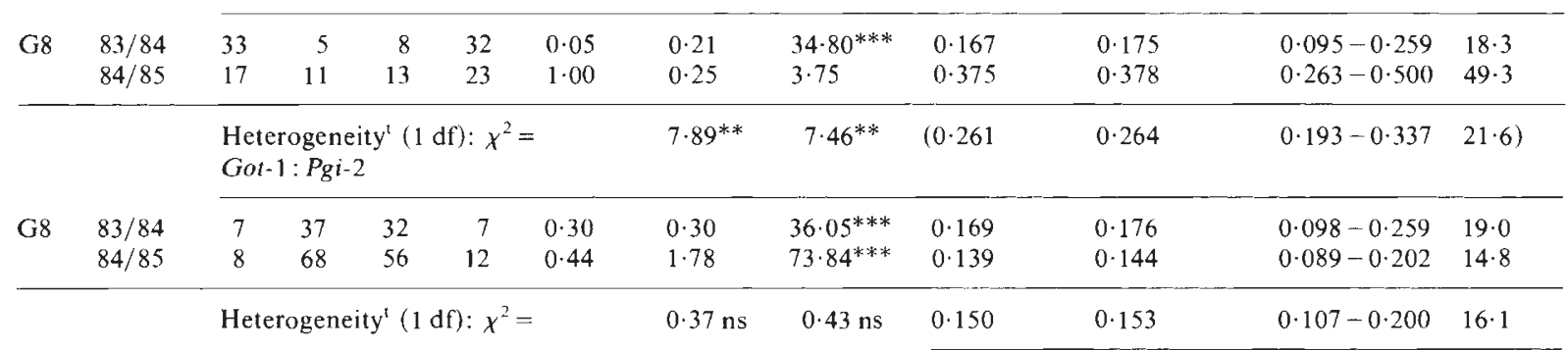

Got-2: Skdh-1

\begin{tabular}{lllrrrrrrrrrrr} 
G1 & $83 / 84$ & 34 & 9 & 7 & 36 & $0 \cdot 00$ & $0 \cdot 19$ & $33 \cdot 91^{* * *}$ & $0 \cdot 186$ & $0 \cdot 193$ & $0 \cdot 113-0 \cdot 277$ & $20 \cdot 4$ \\
& $84 / 85$ & 36 & 6 & 15 & 34 & $0 \cdot 54$ & $1 \cdot 33$ & $27 \cdot 31^{* * *}$ & $0 \cdot 231$ & $0 \cdot 237$ & $0 \cdot 152-0 \cdot 324$ & $25 \cdot 8$ \\
G2 & $83 / 84$ & 20 & 18 & 23 & 20 & $0 \cdot 31$ & $0 \cdot 31$ & $0 \cdot 01$ & $0 \cdot 500$ & $0 \cdot 456$ & $0 \cdot 391-0 \cdot 500$ & $77 \cdot 0$ & 0 \\
G7 & $83 / 84$ & 25 & 27 & 23 & 25 & $0 \cdot 16$ & $0 \cdot 16$ & $0 \cdot 00$ & $0 \cdot 500$ & $0 \cdot 461$ & $0 \cdot 403-0 \cdot 500$ & $80 \cdot 1$ \\
& $84 / 85$ & 24 & 6 & 9 & 18 & $0 \cdot 16$ & $1 \cdot 42$ & $12 \cdot 35^{* * *}$ & $0 \cdot 263$ & $0 \cdot 271$ & $0 \cdot 161-0 \cdot 387$ & $30 \cdot 4$ \\
\hline
\end{tabular}

Lap-2: Pgi-2

\begin{tabular}{|c|c|c|c|c|c|c|c|c|c|c|c|c|}
\hline TH97 & $83 / 84$ & 17 & 36 & 35 & 23 & $0 \cdot 22$ & 0.44 & $8 \cdot 84^{* *}$ & $0 \cdot 361$ & $0 \cdot 363$ & $0.275-0.452$ & $46 \cdot 0$ \\
\hline & $84 / 85$ & 7 & 14 & 11 & 5 & 0.67 & 0.03 & $4 \cdot 47^{*}$ & 0.324 & 0.332 & $0.189-0.500$ & $40 \cdot 0$ \\
\hline G2 & $83 / 84$ & 18 & 24 & 34 & 34 & $6 \cdot 14^{*}$ & $0 \cdot 33$ & $0 \cdot 50$ & $0 \cdot 500$ & 0.457 & $0.326-0.500$ & $77 \cdot 6$ \\
\hline \multirow{2}{*}{ G1 } & $83 / 84$ & 14 & 13 & 14 & 18 & 0.42 & $0 \cdot 15$ & $0 \cdot 39$ & $0 \cdot 500$ & 0.439 & $0 \cdot 349-0.500$ & $68 \cdot 4$ \\
\hline & & $\mathrm{He}$ & - & & & & $8 \cdot 31 \mathrm{~ns}$ & $3.49 \mathrm{~ns}$ & 0.409 & 0.410 & $0.360-0.461$ & $48 \cdot 4$ \\
\hline
\end{tabular}

\begin{tabular}{|c|c|c|c|c|c|c|c|c|c|c|c|c|}
\hline \multirow[b]{2}{*}{ G1 } & \multirow[b]{2}{*}{$83 / 84$} & \multicolumn{11}{|c|}{ 6-Pgdh-3:Skdh-1 } \\
\hline & & 13 & 15 & 17 & 13 & 0.07 & 0.07 & $0 \cdot 61$ & 0.500 & 0.434 & $0 \cdot 336-0.500$ & $66 \cdot 3$ \\
\hline G2 & $83 / 84$ & 23 & 27 & 19 & 24 & 0.53 & 0.87 & $0 \cdot 03$ & 0.500 & 0.459 & $0 \cdot 389-0.500$ & $78 \cdot 8$ \\
\hline \multirow[t]{3}{*}{ G8 } & $83 / 84$ & 18 & 27 & 34 & 21 & $1 \cdot 00$ & $0 \cdot 16$ & $4 \cdot 67^{*}$ & $0 \cdot 390$ & 0.392 & $0 \cdot 298-0.500$ & $52 \cdot 8$ \\
\hline & $84 / 85$ & 41 & 45 & 31 & 36 & $2 \cdot 36$ & 0.53 & 0.03 & $0 \cdot 500$ & $0 \cdot 468$ & $0.421-0.500$ & $85 \cdot 2$ \\
\hline & \multicolumn{6}{|c|}{ Heterogeneity $(3 \mathrm{df}): \chi^{2}=$} & $3.68 \mathrm{~ns}$ & $25 \cdot 4 \mathrm{~ns}$ & 0.477 & 0.467 & $0.421-0.500$ & $60 \cdot 5$ \\
\hline
\end{tabular}

${ }^{*} P<0.05,{ }^{* *} P<0.01, * * * P<0.001 ;$ ns, not significant; ${ }^{\mathrm{t}}$, first $\chi^{2}$ value refers to $\hat{\theta}_{1}$, second to $\hat{\theta}_{2}$.

nation rate is high and vice versa. Tight linkage blocks were indicated for certain two-locus combinations. Got-1 was linked tightly to Pgi-2 and to Dia-2. For these two-locus combinations one tree with seed samples of different crops was available. Pooled over the two seed samples recombination frequencies (Bayes estimates) for Dia-2: Got-1, Dia-2: Pgi-2, and Got-1:Pgi-2 were 0.316, 0.264, 
and $0 \cdot 153$, respectively. Got $-2: S k d h-1$ could be analysed employing the seeds of three trees. For two of them seed samples of different years were available. Whereas for tree G1 very similar results were obtained when calculating $\hat{\theta}$ based on the two seed samples, $\hat{\theta}$ for G7 differed strongly between the two years. Pooled over all seed samples and trees $\hat{\theta}_{2}$ of 0.344 was calculated. Lap2: Pgi-2 showed moderate linkage resulting in $\hat{\theta}_{2}$ of 0.410 , when the data of five seed samples of three trees were considered. The gamete frequencies of tree $\mathrm{G} 1$ resulted in contradictory $\hat{\theta}$ estimates with one sample showing linkage, the other not. 6-Pgdh-3 and $S k d h-1$ seem to be also moderately linked in one of the three investigated trees. This combination showed moderate linkage in one tree with a $\hat{\theta}_{2}$ of $0 \cdot 392$, whereas the other seed sample of the same tree and the two other trees showed no linkage.

A tentative map of the gene loci is given in fig. 1. Lap-2 was found to be linked to Pgi-2. However no tree was available to study linkage between Lap-2 and either Got-1 or Dia-2. Therefore Lap-2 could be located on the other side of this linkage group.

\section{DISCUSSION}

\section{Segregation distortion}

Some enzymes seem to exhibit more frequent segregation distortion than others. There are several studies in conifers, which show that GOT, LAP, 6-PGDH, and APH often do not segregate in the expected 1:1 ratio (cf. Strauss and Conkle, 1986). At the $G d h$ locus Cheliak et al. (1987) found segregation distortion in Norway spruce. In the present study segregation distortions were observed at $I d h-1$ and $P g i-2$ pooled over all trees. Several factors could contribute to such meiotic drive processes and/or gametic selection. Distortion genes linked to isozyme gene loci or linkage of embryonic lethal genes and the respective

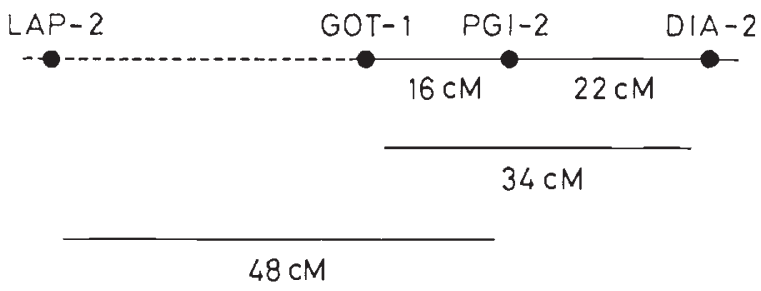

Figure 1 Schematic linkage map in Picea abies. isozyme gene locus can cause segregation distortion. Viability selection after fertilization can also contribute to segregation distortion because only those maternal gametes could be scored that were associated with viable embryos.

\section{Linkage}

The presented data indicate that $M d h-3, I d h-1$, 6-Pgdh-2, 6-Pgdh-3, Gdh-1, Got-2, Pgm-1, Aph-2, and Lap-2 are not linked in $P$. abies. This is in good agreement with the results elaborated in earlier studies in this tree species. Our data confirm six pair-wise combinations, which were also analysed by Lundkvist (1979) and resulted in free recombination in $P$. abies.

Out of 29 two-locus combinations also investigated by Muona et al. (1987) the data of the present study confirm their findings of 27 combinations. One of their pair-wise comparisons showed weak linkage $\left(A p h-2: G d h-1 ; \hat{\theta}_{1}=0 \cdot 417\right)$ in one of three trees analysed. However, linkage between these loci could not be confirmed in any of the three trees of the present study analysing in total 287 gametes. The moderate linkage of Lap-2:Pgi-2 found in our material was not observed by Muona et al. (1987). However, in two of our five samples linkage was not found to be significant and the estimated distance between these loci was about $48 \mathrm{cM}$. Estimated recombination frequencies of Got-1:Pgi-2, Dia-2:Pgi-2, and Dia-2:Got-1 of our material were in the same frame and increased in identical order as found by Muona et al. (1987). An earlier linkage study in Norway spruce indicated the following linkage groups (Poulson et al. 1983):

(1) Lap-1:Got-3:6-Pgdh-3, (Got-3 is considered to be identical with Got-2 of this study)

(2) $M d h-2: M d h-3$,

(3) Got-1: Lap-2.

Concerning linkage in many loci analysed in their study there is agreement with our results. However linkage of Got-2:6-Pgdh-3 could not be confirmed in any of the eight trees regarding 832 gametes. The one tree tested for of Lap-1:Got-2, also showed no linkage. The linkage blocks of $M d h$ 2: Mdh-3 and Got-1:Lap-2 could not be studied in the present investigation. Linkage of Pgi-2 and 6-Pgdh-2, 3 in P. glauca (King and Dancik, 1983) is not supported by our data.

Significant linkage was found in tree G8 between 6-Pgdh-3 and $S k d h-1$ analysing seed of crop $83 / 84$. But the other three seed samples included indicate no linkage. The different $\theta$ esti- 
mates among two seed samples of G8, as well as no linkage in the other trees leads us to expect free combination of these loci. Muona et al. (1987) investigated this combination employing one Norway spruce clone and also found no linkage.

The recombination rates varied among the tested trees but environmental as well as genetic factors could contribute to this phenomenon (Allard, 1963; Grell, 1966; Moran et al., 1983). Thus mapping of isozyme gene loci can only be tentative in this study. The numbers of trees investigated were fairly small. Nevertheless our mapping is in agreement with the findings in other Pinaceae (see gene mapping in five Pinus species reviewed in Conkle, 1981). Lap-2 may be located either on the right or left of Pgi-2. Since Poulsen et al. (1983) have calculated a map distance between Got-1 and Lap- 2 of about $20 \mathrm{cM}$, it is more probable that $L a p-2$ is located on the left of Pgi-2 when regarding our estimated distances. Also Aco could be part of this linkage block (Cheliak et al., 1987). Especially striking is the highly conservative linkage group of Got-1 and Pgi-2 resulting in a distance estimate of $16 \mathrm{cM}$ which agrees well with other studies in the Picea genus (King and Dancik, 1983; Boyle and Morgenstern, 1985; Barret et al., 1987; Muona et al. 1987).

Acknowledgements The authors wish to thank Dr H.-J. Muhs and an anonymous reviewer for critical comments on earlier drafts of the manuscript and D. Krusche for the help in computer programming. Technical assistance of Claudia Lüder and Gabriele Thedens is gratefully acknowledged.

\section{REFERENCES}

ADAMS, W. T. AND JOLY, R. J. 1980. Linkage relationships among twelve allozyme loci in loblolly pine. J. Hered., 71, $33-40$.

ALLARD, R. W. 1983. Evidence for genetic restriction of recombination in the Lima bean. Genetics, 48, 1389-1395.

BARRET, J. W., CHELJAK, W. M. AND KNOWLES, P. 1987. Variation at the PGI/AAT linkage group between populations of black spruce. Can. J. For. Res., 17, 756-758

bergmann, F. 1973. Genetische Untersuchungen bei Picea abies mit Hilfe der Isoenzym-Identifizierung. II. Genetische Kontrolle von Esterase- und Leucinaminopeptidase-Isoenzymen im haploiden Endosperm ruhender Samen. Theor. Appl. Genet., 43, 222-225.

BERGMANN, F. 1974. The genetics of some isoenzyme systems in spruce endosperm (Picea abies). Genetica, 6, 353-360.

BOYLE, T. J. AND MORGENSTERN, E. K. 1985. Inheritance and linkage relationships of some isozymes of black spruce in New Brunswick. Can. J. For. Res. 15, 992-996.

CHELIAK, W. M., MORGAN, K., DANCIK, B. P., STROBECK, C. AND YF.H, F. C. H. 1984. Segregation of allozymes in megagemetophytes of viable seed from a natural population of jack pine, Pinus banksiana Lamb. Theor. Appl. Genet, 69, 145-151.
CHELIAK, W. M. ANID PITEL, J. A. 1985. Inheritance and linkage of allozymes in Larix laricina. Silvae Genet., 34, 142-148.

CHELIAK, W. M., SKROPPA, T, AND PITEL, J. A. 1987. Genetics of the polycross. 1. Experimental results from Norway spruce. Theor. Appl. Genet, 73, 321-329

CONKLE, M. T. 1981. Isozyme variation and linkage in six conifer species In Proc. Symp. Isozymes of North American Forest Trees and Forest Insects. USDA For. Serv. Gen. Tech. Rep., PSW-48, pp. 11-17.

CONKLE, M. T., HODGSKISS, P. D., NUNNALLY, L. B. AND HUNTER, S. C. 1982. Starch gel electrophoresis of conifer seeds: a laboratory manual. Gen. Tech. Rep. PSW-64, Berkley, CA, USDA, p. 18.

ECKERT, R. R., JOLY, R. J. ANI NEALE, D. B. 1981. Genetics of isozyme variants and linkage relationships among allozyme loci in eastern white pine clones. Can. J. For. Res., 11, 573-579.

FURNIER, G. R., KNOWLES, P., ALEKSIUK, M. A. AND DANCIK, B. P. 1986. Inheritance and linkage in allozymes in seed tissue of whitebark pine. Can. J. Genet. Cytol., 28, 601-604.

FISHER, R. A. 1937. The design of experiments. Oliver and Boyd, Edinburgh

FREI, O. M., STUBER, C. W. AND GOODMAN, M. M. 1986. Use of allozymes as genetic markers for predicting performance in maize single cross hybrids. Crop Sci., 26, 37-41.

GEBUREK, TH. AND WANG, Q.-H. Inheritance of isozyme polymorphisms and their linkage relations in Chinese fir ( $\mathrm{Cun}$ ninghamia lanceolata (Hook)). Hereditas, (submitted).

GEBUREK, TH., SC.HOLZ, F., KNABE, W. AND VORNWEG, A. 1987. Genetic studies by isozyme gene loci on tolerance and sensitivity in an air polluted Pinus sylvestris field trial. Silvae Genet., 36, 49-53.

GURIES, R. P., FRIEDMAN, S. T. AND LEDIG, F. T. 1978. A megagametophyte analysis of genetic linkage in pitch pine (Pinus rigida Mill.). Heredity, 40, 309-314.

GRELL, R. 1966. The meiotic origin of temperature induced crossovers in Drosophila melanogaster females. Genetics, $54,411-421$.

Jeffreys, H. 1961. Theory of Probability. Clarendon Press, Oxford.

KING, J. N. AND DANCIK, B. P. 1983. Inheritance and linkage of isozymes in white spruce (Picea glauca). Can. J. Genet. Cytol., 25, 430-436.

KOSAMBI, B. D. 1944. The estimation of map distance from recombination values. Ann. Eugen. London, 12, 172-175.

LUNDKVIST, K. 1974. Inheritance of leucine aminopeptidase isozymes in Picea abies K. Hereditas, 76, 91-96.

LUNDKVIST, K. 1975. Inheritance of acid phosphatase isozymes in Picea abies K. Hereditas, 79, 221-226.

LUNDKVIST, K. 1979. Allozyme frequency distributions in four Swedish populations of Norway spruce (Picea abies K.). 1. Estimations of genetic variation within and among populations, genetic linkage and a mating system parameter. Hereditas, 90, 127-143.

MATHER. K. 1951. The Measurement of Linkage in Heredity, Methuen \& Co. London.

MÜLLER-STARCK, G. AND LIU, Y.-Q. Genetics of Cunninghamia lanceolata Hook. 1. Genetic analysis. Silvae Genet,, (in press).

MORAN, G. F., BFlL, J. C. AND HILLIKER, A. J. 1983. Greater meiotic recombination in male vs. female gametes in Pinus radiata. J. Hered., 74, 62.

MUONA, O., YAZIDANI, R. AND LINDQUIST, G. 1987. Analysis of linkage in Picea abies. Hereditas, 106, 31-36.

NORDHEIM, F. V., O'MALLEY, D. M. AND GURIES, R. P. 1983. Estimation of recombination frequency in genetic linkage studies. Theor. Appl. Genet., 66, 313-321. 
OMALley, D. M., GURIES, R. P. AND NORDHEIM, E. V. 1986. Linkage analysis for 18 enzyme loci in Pinus rigida Mill. Theor. Appl. Genet., 72, 530-535.

POULSEN, H. D., SIMONSEN, V. AND WELLENDORF, H. 1983. The inheritance of six isozymes in Norway spruce (Picea abies (L.) Karst.). Forest Tree Improv., 16, 12-33.

RAO, C. R. 1973. Linear Statistical Inference and Its Application. John Wiley and Sons, New York.

RUDiN, D. AND EKBerg, I. 1978. Linkage studies in Pinus sylvestris L. using macro gametophyte allozymes. Silvae Genet., 27, 1-12.
SHIRAISHI, S., 1988. Linkage relationships among allozyme loci in Japanese black pine, Pinus thunbergii Parl. Silvae Genet., $37,60-66$.

STRAUSS, S. H. AND CONKLE, M. T. 1986. Segregation, linkage, and diversity of allozymes in knobcone pine. Theor. Appl. Genet., 72, 483-493.

TIGERSTEDT, P. M. A. 1973. Studies on isozyme variation in marginal and central populations of Picea abies. Hereditas, $75,47-60$. 